\title{
ANALISIS KUALITAS LAYANAN PERPUSTAKAAN KAMPUS B UNIVERSITAS AIRLANGGA MELALUI INTEGRASI IMPORTANCE PERFORMANCE ANALYSIS (IPA), DAN MODEL KANO SERTA USULAN PERBAIKANNYA MENGGUNAKAN CAUSE AND EFFECT DIAGRAM
}

\author{
Fatorahman \\ Email: ddfathur1@gmail.com \\ Yetty Dwi Lestari \\ Departemen Manajemen Fakultas Ekonomi dan Bisnis Universitas Airlangga
}

\begin{abstract}
The aims of this study to identify the attributes of existing service quality on B Campus Library of Airlangga University as well as determine the level of priority level of each need by integrating models and Kano methods, Importance Performance Analysis, furthermore, it also identyifying the root causes of the three attributes of service quality on B Campus Library of Airlangga University were entered into the forth kuadrant by using Cause and Effect Diagram, and give recommendation for improvement based on problems identification by Cause and Effect Diagram. The approach used in this research is a qualitative approach with the kind of descriptive research. Data used are primary and secondary data. Analysisi data used descriptive analysis with the help of IBM SPSS Statistics 20 and Microsoft Office Excel.

This research used 23 atributes of service quality. The result of the classification of data qith kano's mode; stated that 22 atributes of service quality. The results of the classification of data with Kano's model stated that 22 atributes are included into attractive category. Because none of attributes were included into the indifferent category, all of the attributes can be used in the integration of Kano's model and IPA methods. From the integration, comes three attributes of service quality that included into concentrate here area; the availbility of fast connection wifi and internet facilities, friendly, polite, orderly, and neat in officer services, and the availability of clean toilet facilities.

The root of the problem cause the lack of quality in three attributes identified by Cause and Effect Diagram based on interviews with the B Campus Library of Airlangga University and also based on the author's observation results. Based on the identification of the three atributes with the quality of service, proposed recommendation to fix problem on each attributes. The recommendation includes several root of the problem, such as man, methods, equipment, and environment
\end{abstract}

Keyword: Service Quality of B Campus Library of Airlangga University, Kano's model, Importance-Performance Analysis, and Cause and Effect Diagram 


\section{Fatrahman}

\section{Yetti Dwi Lestari}

\section{A. PENDAHULUAN}

Perpustakaan adalah organisasi, berupa lembaga atau unit kerja yang bertugas menghimpun koleksi pustaka dan menyediakannya bagi masyarakat untuk dimanfaatkan. Lembaga merupakan organisasi yang otonom, sedang unit kerja merupakan organisasi di dalam organisasi, sehingga memiliki lembaga induk (Soeatminah,1992). Dalam dunia perpustakaan, kualitas pelayanan merupakan suatu hal yang sangat penting untuk diwujudkan, karena merupakan ujung tombak perpustakaan. Seperti yang disampaikan (Soeatminah, 1992) yang mengatakan bahwa, baik dan tidaknya perpustakaan tergantung bagaimana pelayananya, sebab bagian pelayanan inilah yang berhubungan langsung dengan pengguna perpustakaan.

Model Kano dikembangkan oleh Noriaki kano (Kano, 1984). Model Kano dikembangkan oleh Noriaki kano (Kano, 1984). Model kano merupakan model yang menyediakan alat yang efektif untuk mengkategorikan kebutuhan dan untuk memahami keputusan mereka (Matzler dan Hiterhuber, 1998), konsumen perlu ditingkatkan karena kondisi saat ini belum memuaskan.

Dalam penelitian ini, penulis memilih menggunakan integrasi antara model IPA-Kano yang digunakan sebagai alat baru untuk mengelompokkan dan mendiagnosa atribut kualitas layanan dan memberikan strategi khusus untuk atribut dalam setiap kategori. Integrasi model IPA-Kano dapat menghindari keterbatasan model Kano yang mengabaikan kinerja atribut dan kepentingan, selain itu juga untuk menghilangkan kelemahan model IPA yang mempertimbangkan hanya satu-dimensi kualitas.(Kuo dkk., 2012).

Berdasarkan latar belakang masalah yang telah diuraikan, kami dapat merumuskan masalah sebagai berikut jasa yang perlu mendapat:

1. Bagaimana penentuan prioritas perbaikan kualitas layanan jasa yang dihasilkan Perpustakaan Kampus B Universitas Airlangga melalui integrasi model IPA dan Model Kano?

2. Bagaimana usulan rancangan perbaikan kualitas layanan yang dihasilkan melalui Cause and Effect diagram?

Tujuan dari penelitian ini yaitu:

A. Menentukan prioritas perbaikan kualitas layanan jasa yang dihasilkan Perpustakaan Kampus B Universitas Airlangga melalui integrasi model IPA dan Model Kano

B. Mengusulkan rancangan perbaikan kualitas layanan yang dihasilkan melalui Cause and Effect diagram 


\section{Jurnal Manajemen Teori dan Terapan Tahun 8. No. 2, Agustus 2015}

\section{B. LANDASAN TEORI}

\section{KUALITAS}

Kualitas telah dipandang sebagai factor kunci dari menentukan kelangsungan hidup suatu bisnis serta adanya keuntungan jangka panjang yang sangat penting baik pada industry manufaktur maupun jasa ( Sahney dkk, 2003). Belum adanya definisi yang terpadu yang dapat menjelaskan tentang apa itu kualitas dan pengembangannya yang bias diterima secara oleh kualitas global. Pada sudut pandang tradisional, kualitas dipandang sebagai kecocokan suatu produk terhadap spesifikasinya (Foster: 2004). Thio (2001) mendefinisikan kualitas sebagai suatu ukuran yang mengukur kemampuan suatu bisnis dalam memenuhi kebutuhan konsumennya.

\section{KEPUASAN PELANGGAN}

Kotler (2004) yang menyatakan bahwa kepuasan pelanggan yaitu tingkatan dimana anggapan kinerja (perceived performance) produk akan sesuai dengan harapan seorang pelanggan. Harapan pelanggan dapat didefinisikan secara tepat apabila perusahaan mengerti persepsi pelanggan terhadap kepuasan. Mengetahui persepsi pelanggan terhadap kepuasan sangatlah penting agar tidak terjadi kesenjangan (gap) persepsi antara perusahaan dengan pelanggan. Kepuasan pelanggan mencakup perbedaaan antara harapan dan kinerja atau hasil yang dirasakan (Tjiptono,2011).

\section{SERVQUAL}

Menurut Zeithaml, dkk, dalam Yamit (2005) telah melakukan berbagai penelitian terhadap beberapa jenis jasa, dan berhasil mengidentifikasi lima dimensi karakteristik yang digunakan oleh para pelanggan dalam mengevaluasi kualitas pelayanan. Kelima dimensi karakteristik kualitas pelayanan tersebut adalah :

1. Tangibles (bukti langsung), yaitu meliputi fasilitas fisik, perlengkapan, pegawai, dan sarana komunikasi.

2. Reliability (kehandalan), yaitu kemampuan dalam memberikan pelayanan dengan segera dan memuaskan serta sesuai dengan telah yang dijanjikan.

3. Responsiveness (daya tangkap), yaitu keinginan para staf untuk membantu para pelanggan dan memberikan pelayanan dengan tanggap.

4. Assurance (jaminan), yaitu mencakup kemampuan, kesopanan dan sifat dapat dipercaya yang dimiliki para staf, bebas dari bahaya, resiko ataupun keragu-raguan.

5. Empathy, yaitu meliputi kemudahan dalam melakukan hubungan, komunikasi yang baik, dan perhatian dengan tulus terhadap kebutuhan pelanggan.

\section{Importance Performance Analysis (IPA)}

Metode Importance_Performace Anaysis pertama kali diperkenalkan oleh martilla dan James pada tahun 1977 (Yuhazri, 2012). Teknik ini pada awalnya diperkenalkan sebagai cara untuk 
Fatrahman

Yetti Dwi Lestari

memeriksa kepuasan pelanggan sebagai fungsi dari apa yang "pentin (importance)" bagi pelanggan dan bagaimana "kinerja (performance)" menurut pelanggan (Kuo dkk., 2011).

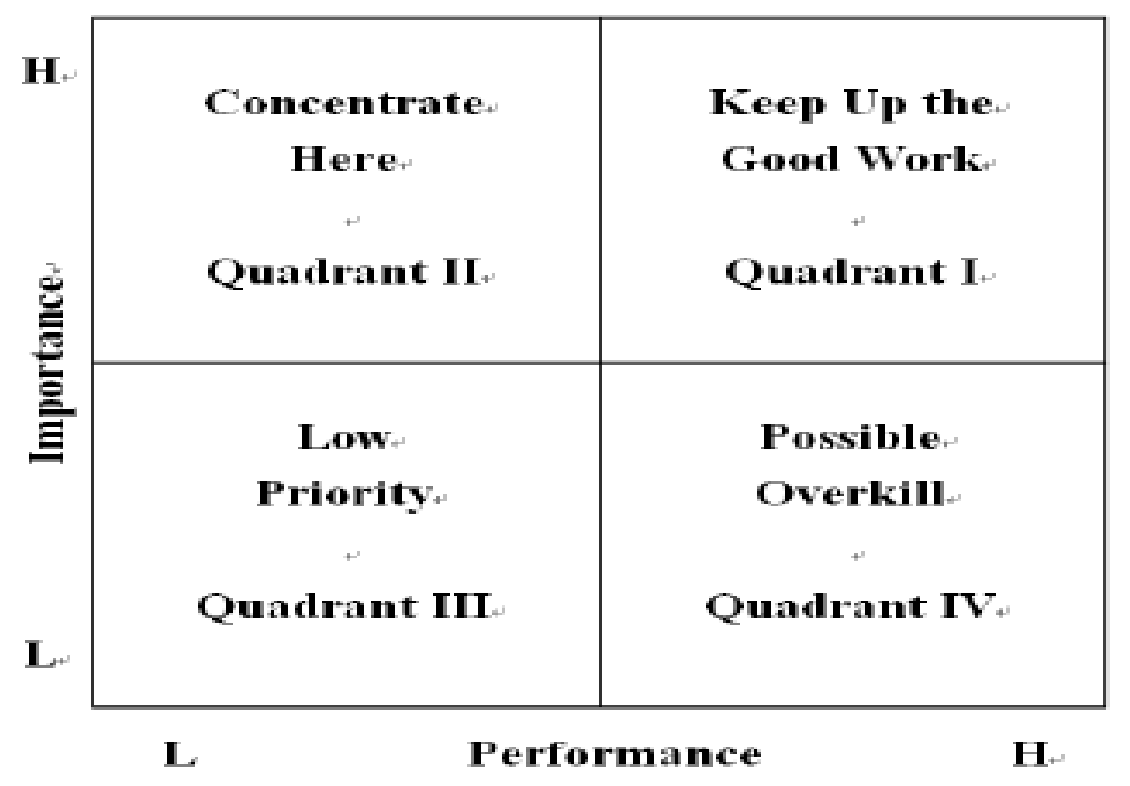

Gambar B.1 grafik model Importance-Performance Analysis

Sumber: Kuo, Y. -F., Chen, J. -Y. and Deng, W. -J. , IPA-Kano model: A new tool for categorizing and diagnosing service quality attributes, Total Quality Management \& Business Excellence, dx.doi.org/10.1080/14783363.2011.637811

Yuhazri dkk (2012) memberikan penjelasan masing-masing quadran dalam grafik IPA seperti berikut:

1. Kuadran I (Keep Up The Good Work). Meliputi atribut yang sangat penting untuk responden, dan pada saat yang sama, organisasi ini tampaknya memiliki tingkat kinerja yang tinggi dalam kegiatan ini

2. Kuadran II (Concentrate Here). Meliputi atribut yang dianggap sangat penting bagi responden, namun tingkat kinerjanya cukup rendah.

3. Kuadran III (Low Priority). Atribut disini dinilai memiliki kepentingan yang rendah dan kinerja yang redah pula.

4. Kuadran IV (Possible Overkill). Kuadran ini mengandung atribut dimana pelanggan merasa tidak terlalu penting, namun kinerja perusahaan terasa berbebihan.

\section{Model Kano}

Menurut King dalam Bayraktaroglu et al. (2007) terdapat tiga kategori utama dalam model Kano: 


\section{Jurnal Manajemen Teori dan Terapan Tahun 8. No. 2, Agustus 2015}

1. Must be (basic) needs : Kebutuhan ini sdangat mendasar karena tidak diungkapkan secara langsung oleh pelanggan..

2. One-dimensional (performance) needs : Jika kepuasan terhaap kebutuhan ini dapat terpenuhi dengan peningkatan kinerja, kepuasan pelanggan akan meningkat.

3. Attractive (excitement) needs :. Tidak adanya kebutuhan ini tidak akan menyebabkan ketidakpuasan pelanggan, karena pelanggan tidak menyadari adanya kebutuhan ini. Apabila kebutuhan ini dapat dipenuhi, pelanggan akan merasa lebih puas. Selain kategori utama yang telah dijelskan di atas, bisa juga muncul tiga kategori lain, yaitu:

1. Indifferent (tak peduli) : Berarti bahwa pelanggan tidak peduli dengan adanya atribut ini, dan tidak terlalu tertarik apakah atribut ini hadir atau tidak.

2. Questionable ( diragukan) : Situasi ini muncul ketika terdapat kontradiksi pada jawaban pelanggan dalam pertanyaan pasangan.

3. Reverse( kemunduran) : Berarti bahwa beberapa keputusan responden menurun dengan adanya pertanyaan ini, namun mereka juga mengharapkan kebalikan dari itu.

Tabel B.1 Evaluasi Kategori Kano

\begin{tabular}{|l|l|l|l|l|l|l|}
\hline \multicolumn{2}{|l|}{ Customer Requirements } & Dysfunctional \\
\cline { 2 - 7 } \multicolumn{2}{|l|}{} & Like & Must-be & Neutral & Live with & Dislike \\
\hline \multirow{3}{*}{ Functional } & Like & Q & A & A & A & O \\
\cline { 2 - 7 } & Must-be & R & I & I & I & M \\
\cline { 2 - 7 } & Neutral & R & I & I & I & M \\
\cline { 2 - 7 } & Live with & R & I & I & I & M \\
\cline { 2 - 7 } & Dislike & R & R & R & R & Q \\
\hline
\end{tabular}

A: Attractive, O: One-dimensional, M: Must-be, I: Indifferent, R: Reverse, Q: Questionable

Sumber: Kuo, Y. -F., Chen, J. -Y. and Deng, W. -J. , IPA-Kano model: A new tool for categorizing and diagnosing service quality attributes, Total Quality Management \& Business Excellence, dx.doi.org/10.1080/14783363.2011.637811

\section{Cause and Effect Diagram}

Cause and effect diagram adalah suatu diagram yang menunjukkan hubungan nantara sebab dan akibat (Gasperz, 2003). Menurut Lennartsson (2004), diagram ini ditemukan oelh prof, koru ishikawa pada tahun 1953 dan digunakan dalam bentuk pengungkapan pendfapat berikut 


\section{Fatrahman}

\section{Yetti Dwi Lestari}

kemungkinan-kemungkinan untuk mencari pemecaha suatu masalah. Diagram ini bertujuan untuk menganalisis dan menunjukkan factor utama yang berpengaruh pada kualitas dan mempunyai akibat pada suatu masalah. Selain itu, diagram ini juga bertujuanuntuk melihat factor-faktor yang lebih terperinci yang berpengaruh dan mempunyai akibat pada factor utama tersebut.

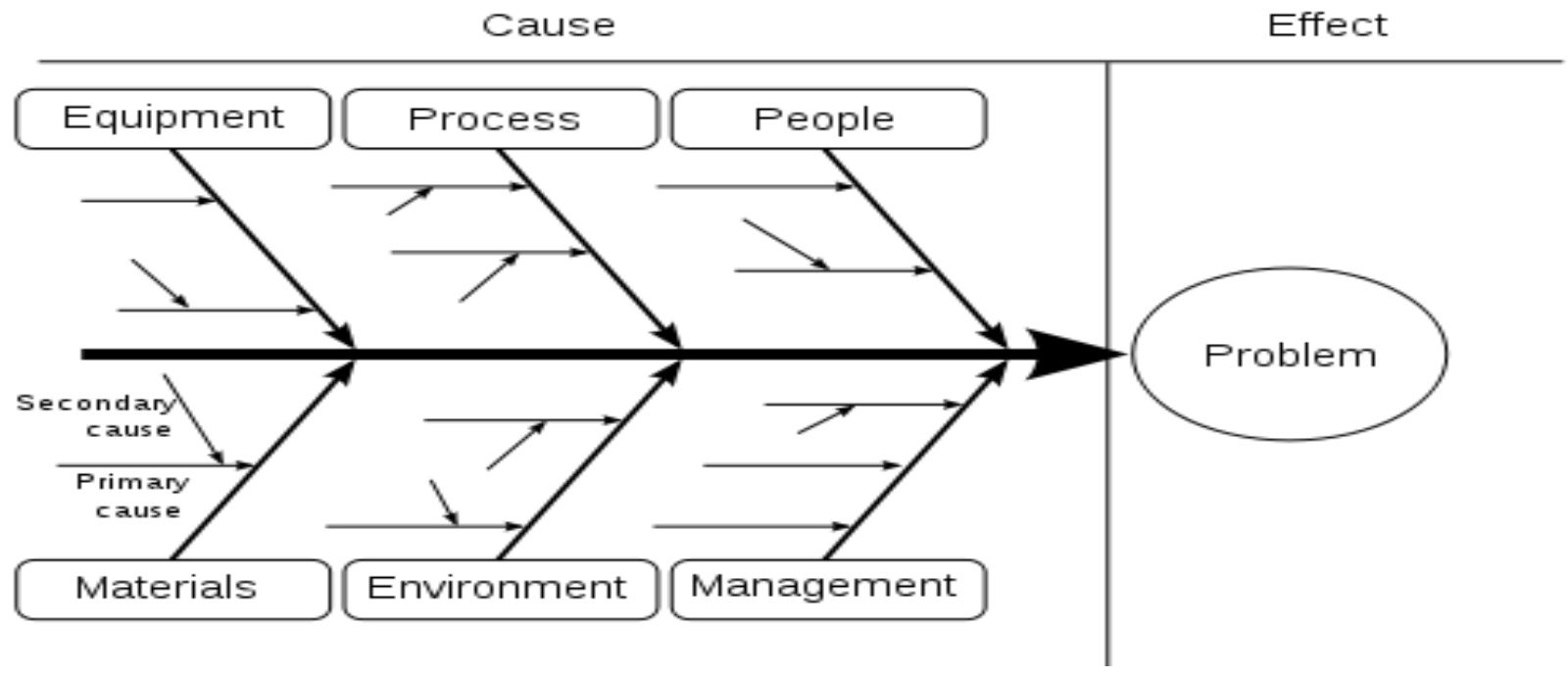

\section{METODE PENELITIAN}

Pendekatan yang digunakan dalam penelitian ini adalah pendekatan kualitatif deskriptif. menurut Sugiyono (2010) metode penelitian kualitatif adalah metode penelitian yang digunakan untuk meneliti kondisi obyek yang alamiah dimana peneliti adalah sebagai instrumen kunci, pengambilan sampel sumber data dilakukan secara purposive sampling dengan metode nonprobability sampling.

\section{Teknik Analisis}

Teknik analisis yang dipakai pada penelitian ini adalah sebagai berikut:

1. Penggunaan metode servqual

- Mengidentifikasi atribut-atribut layanan pada perusahaan menggunakan lima dimensi servqual

2. Penggunaan model Kano

- Pengumpulan data dari kuisioner Kano

- Mengidentifikasi atribut-atribut layanan ke dalam kategori Kano

- Menyusun table evaluasi Kano

- Membuang atribut yang masuk ke dalam kategori Indifferent

3. Penggunaan metode IPA

- Pengumpulan data dari kuisioner IPA 


\section{Jurnal Manajemen Teori dan Terapan Tahun 8. No. 2, Agustus 2015}

-Mengidentifikasi atribut-atribut layanan ke dalam Kuadran IPA berdasarkan tingkat performance dan importance tiap-tiap atribut dengan rumus kuadran.

$$
\bar{X}_{i}=\frac{\sum_{j=i}^{n} X_{i j}}{n} \quad \bar{Y}_{i}=\frac{\sum_{j=i}^{n} Y_{i j}}{n}
$$

4. Integrasi model Kano dan metode IPA

- Mengkombinasikan model kano dan metode IPA

- Menentukan atribut-atribut yang diprioritaskan perbaikannya

4. Cause and Effect Diagram

-Merancang perbaikan dari hasil integrasi IPA-Kano dengan menggunakan Cause and Effect diagram

5. Menarik kesimpulan dan saran

- Memberikan kesimpulan dari penelitian yang sudah dilakukan

- Memberikan usulan rancangan perbaikan kualits layanan.

\section{PEMBAHASAN}

Data Identifikasi Responden

Responden pada penelitian ini adalah 100 orang degan pendistribusian kuisioner sesuai dengan pertimbanga yang telah ditentukan.

Identifikasi Matriks IPA

Tabel D. 1 hasil Pengolahan Kuisioner IPA

\begin{tabular}{|l|l|l|l|l|}
\hline Dimensi & No. & Atribut Pelayanan & Importance & Performance \\
\hline Tangibles & T1 & Ruangan yang bersih dan nyaman & 4,72 & 3,78 \\
\cline { 2 - 5 } & T2 & $\begin{array}{l}\text { Penataan ruangan dan penataan buku } \\
\text { yang rapi }\end{array}$ & 4,68 & 3,64 \\
\cline { 2 - 5 } & T3 & $\begin{array}{l}\text { Kondisi meja dan tempat duduk nyaman, } \\
\text { dan jumlahnya memadai }\end{array}$ & 4,68 & 3,41 \\
\cline { 2 - 6 } & T4 & $\begin{array}{l}\text { Kondisi tempat penitipan barang baik, } \\
\text { dan jumlahnya memadai }\end{array}$ & 3,8 \\
\cline { 2 - 5 } & T5 & $\begin{array}{l}\text { Tersedianya katalog manual dan digital } \\
\text { yang lengkap dan akurat }\end{array}$ & 3,38 \\
\cline { 2 - 5 } & T6 & $\begin{array}{l}\text { Tersedianya fasilitas internet dan wifi } \\
\text { dengan koneksi yang cepat }\end{array}$ & 2,69 \\
\hline
\end{tabular}


Fatrahman

Yetti Dwi Lestari

\begin{tabular}{|c|c|c|c|c|}
\hline & T7 & Tersedianya fasilitas toilet yang bersih & 4,54 & 2,82 \\
\hline & T8 & Desain interior ruangan yang menarik & 4,14 & 3,07 \\
\hline & T9 & Tersedianya tempat parkir yang memadai & 4,35 & 2,72 \\
\hline \multirow[t]{4}{*}{ Reliability } & R1 & $\begin{array}{l}\text { Perpustakaan buka dan tutup tepat } \\
\text { waktu }\end{array}$ & 4,38 & 3,77 \\
\hline & R2 & $\begin{array}{l}\text { Tersedianya koleksi (jurnal, buku, skripsi, } \\
\text { laporan PKL, majalah) yang lengkap }\end{array}$ & 4,66 & 3,4 \\
\hline & R3 & $\begin{array}{l}\text { Koleksi yang tersedia dengan informasi } \\
\text { yang ada sesuai }\end{array}$ & 4,67 & 3,3 \\
\hline & R4 & $\begin{array}{l}\text { Letak koleksi dengan informasi yang } \\
\text { tersedia sesuai }\end{array}$ & 4,59 & 3,22 \\
\hline \multirow[t]{4}{*}{ Responsiveness } & RS 1 & $\begin{array}{l}\text { Petugas membantu pengunjung } \\
\text { mengatasi kesulitan dalam mencari } \\
\text { koleksi dengan cepat }\end{array}$ & 4,52 & 2,82 \\
\hline & RS2 & $\begin{array}{l}\text { Petugas menata kembali buku yang telah } \\
\text { selesai dipergunakan dengan cepat }\end{array}$ & 4,38 & 3,15 \\
\hline & RS3 & $\begin{array}{l}\text { Petugas membantu pengunjung } \\
\text { mengatasi kesulitan dalam mengakses wifi } \\
\text { dengan cepat }\end{array}$ & 4,46 & 2,56 \\
\hline & RS4 & $\begin{array}{l}\text { Petugas menanggapi permohonan } \\
\text { peminjaman buku dengan cepat }\end{array}$ & 4,58 & 3,44 \\
\hline \multirow[t]{3}{*}{ Assurance } & $\mathrm{Al}$ & $\begin{array}{l}\text { Petugas mampu memahami letak tata } \\
\text { ruang Perpustakaan dengan baik dan } \\
\text { benar }\end{array}$ & 4,63 & 3,63 \\
\hline & A2 & $\begin{array}{l}\text { Petugas bersikap ramah, sopan, tertib, } \\
\text { dan rapi dalam melayani pengunjung }\end{array}$ & 4,63 & 3,16 \\
\hline & A3 & $\begin{array}{l}\text { Petugas dapat dihubungi dengan mudah } \\
\text { saat dibutuhkan }\end{array}$ & 4,51 & 3,1 \\
\hline \multirow[t]{3}{*}{ Emphaty } & El & $\begin{array}{l}\text { Petugas mampu memahami kebutuhan } \\
\text { spesifik dari para pengunjung }\end{array}$ & 4,35 & 3,03 \\
\hline & E2 & $\begin{array}{l}\text { Penyampaian keluhan dan saran dari } \\
\text { pelanggan dapat dilakukan dengan } \\
\text { mudah }\end{array}$ & 4,4 & 2,98 \\
\hline & E3 & Petugas memberikan solusi bagi keluhan & 4,46 & 2,95 \\
\hline
\end{tabular}


Jurnal Manajemen Teori dan Terapan

Tahun 8. No. 2, Agustus 2015

\begin{tabular}{|l|l|l|l|}
\hline & pelanggan & & \\
\hline Jumlah Total rata-rata tiap atribut seluruh responden & 104.150 & 74.130 \\
\hline Grand Mean & 4.53 & 3.22 \\
\hline
\end{tabular}

Sumber: Data diolah

1. Kuadran I

- Ruangan yang bersih dan nyaman

- Penataan ruangan dan penataan buku yang rapi

- Kondisi meja dan tempat duduk nyaman, dan jumlahnya memadai

- Kondisi tempat penitipan barang baik, dan jumlahnya memadai

- Tersedianya katalog manual dan digital yang lengkap dan akurat

- Tersedianya koleksi (jurnal, buku, skripsi, laporan PKL, majalah) yang lengkap

- Koleksi yang tersedia dengan informasi yang ada sesuai

- Petugas menanggapi permohonan peminjaman buku dengan cepat

- Petugas mampu memahami letak tata ruang Perpustakaan dengan baik dan benar

2. Kuadran II

- Tersedianya fasilitas internet dan wifi dengan koneksi yang cepat

- Tersedianya fasilitas toilet yang bersih

- Petugas bersikap ramah, sopan, tertib, dan rapi dalam melayani pengunjung

3. Kuadran III

- Desain interior ruangan yang menarik

- Tersedianya tempat parkir yang memadai

- Petugas menata kembali buku yang telah selesai dipergunakan dengan cepat

- Petugas membantu pengunjung mengatasi kesulitan dalam mengakses wifi dengan cepat

- Petugas dapat dihubungi dengan mudah saat dibutuhkan

- Petugas mampu memahami kebutuhan spesifik dari para pengunjung

- Penyampaian keluhan dan saran dari pelanggan dapat dilakukan dengan mudah

- Petugas memberikan solusi bagi keluhan pelanggan

4. Kuadran IV

- Perpustakaan buka dan tutup tepat waktu

\section{Model Kano}


Tabel D. 2 Hasil Kuisioner Kano

\begin{tabular}{|c|c|c|c|c|c|c|c|c|}
\hline Dimensi & Atribut & $A$ & 0 & $M$ & I & $\mathrm{R}$ & $Q$ & $\begin{array}{l}\text { KATEGORI } \\
\text { KANO }\end{array}$ \\
\hline \multirow[t]{9}{*}{ Tangibles } & $\mathrm{Tl}$ & 15 & 64 & 20 & 1 & - & - & 0 \\
\hline & T2 & 13 & 59 & 21 & 7 & - & - & $\mathrm{O}$ \\
\hline & T3 & 24 & 40 & 24 & 11 & 1 & - & 0 \\
\hline & $\mathrm{T} 4$ & 24 & 42 & 19 & 14 & 1 & - & 0 \\
\hline & T5 & 18 & 35 & 18 & 28 & 1 & - & 0 \\
\hline & T6 & 16 & 52 & 20 & 11 & 1 & - & $\mathrm{O}$ \\
\hline & $\mathrm{T7}$ & 10 & 57 & 23 & 10 & & - & $\mathrm{O}$ \\
\hline & T8 & 28 & 23 & 13 & 35 & 1 & - & $A$ \\
\hline & T9 & 15 & 35 & 19 & 31 & - & - & 0 \\
\hline \multirow[t]{4}{*}{ Reliability } & Rl & 24 & 30 & 14 & 32 & - & - & 0 \\
\hline & R2 & 22 & 45 & 17 & 16 & - & - & $\mathrm{O}$ \\
\hline & R3 & 18 & 43 & 19 & 20 & - & - & 0 \\
\hline & R4 & 19 & 45 & 16 & 20 & - & - & $\mathrm{O}$ \\
\hline \multirow[t]{4}{*}{ Responsiveness } & RS 1 & 18 & 35 & 24 & 23 & - & - & $\mathrm{O}$ \\
\hline & RS2 & 21 & 34 & 18 & 27 & - & - & $\mathrm{O}$ \\
\hline & RS3 & 10 & 35 & 27 & 28 & 1 & - & $\mathrm{O}$ \\
\hline & RS4 & 16 & 45 & 22 & 17 & - & - & O \\
\hline \multirow[t]{3}{*}{ Assurance } & $\mathrm{Al}$ & 9 & 55 & 18 & 18 & - & - & $\mathrm{O}$ \\
\hline & $\mathrm{A} 2$ & 13 & 60 & 15 & 12 & - & - & O \\
\hline & A3 & 11 & 41 & 25 & 23 & - & - & O \\
\hline \multirow[t]{3}{*}{ Emphaty } & El & 19 & 25 & 21 & 35 & - & - & $\mathrm{O}$ \\
\hline & E2 & 19 & 28 & 21 & 32 & - & - & $\mathrm{O}$ \\
\hline & E3 & 18 & 29 & 20 & 33 & - & - & $\mathrm{O}$ \\
\hline
\end{tabular}

Sumber: Data diolah Integrasi IPA dan Kano 
Tabel D.3 Integrasi Kualitas Pelayanan Model IPA Kano

\begin{tabular}{|c|c|c|c|c|c|c|c|c|}
\hline Dimensi & Atribut & A & $\mathrm{O}$ & $M$ & I & $R$ & Q & $\begin{array}{l}\text { KATEGORI } \\
\text { KANO }\end{array}$ \\
\hline \multirow[t]{9}{*}{ Tangibles } & $\mathrm{Tl}$ & 15 & 64 & 20 & 1 & - & - & 0 \\
\hline & $\mathrm{T} 2$ & 13 & 59 & 21 & 7 & - & - & 0 \\
\hline & T3 & 24 & 40 & 24 & 11 & 1 & - & $\mathrm{O}$ \\
\hline & T4 & 24 & 42 & 19 & 14 & 1 & - & 0 \\
\hline & T5 & 18 & 35 & 18 & 28 & 1 & - & O \\
\hline & T6 & 16 & 52 & 20 & 11 & 1 & - & O \\
\hline & T7 & 10 & 57 & 23 & 10 & & - & 0 \\
\hline & T8 & 28 & 23 & 13 & 35 & 1 & - & A \\
\hline & T9 & 15 & 35 & 19 & 31 & - & - & 0 \\
\hline \multirow[t]{4}{*}{ Reliability } & R1 & 24 & 30 & 14 & 32 & - & - & $\mathrm{O}$ \\
\hline & R2 & 22 & 45 & 17 & 16 & - & - & $\mathrm{O}$ \\
\hline & R3 & 18 & 43 & 19 & 20 & - & - & $\mathrm{O}$ \\
\hline & R4 & 19 & 45 & 16 & 20 & - & - & $\mathrm{O}$ \\
\hline \multirow[t]{4}{*}{ Responsiveness } & RS 1 & 18 & 35 & 24 & 23 & - & - & O \\
\hline & RS2 & 21 & 34 & 18 & 27 & - & - & O \\
\hline & RS3 & 10 & 35 & 27 & 28 & 1 & - & $\mathrm{O}$ \\
\hline & RS4 & 16 & 45 & 22 & 17 & - & - & $\mathrm{O}$ \\
\hline \multirow[t]{3}{*}{ Assurance } & $\mathrm{Al}$ & 9 & 55 & 18 & 18 & - & - & $\mathrm{O}$ \\
\hline & $\mathrm{A} 2$ & 13 & 60 & 15 & 12 & - & - & $\mathrm{O}$ \\
\hline & A3 & 11 & 41 & 25 & 23 & - & - & $\mathrm{O}$ \\
\hline \multirow[t]{3}{*}{ Emphaty } & El & 19 & 25 & 21 & 35 & - & - & $\mathrm{O}$ \\
\hline & E2 & 19 & 28 & 21 & 32 & - & - & $\mathrm{O}$ \\
\hline & E3 & 18 & 29 & 20 & 33 & - & - & $\mathrm{O}$ \\
\hline
\end{tabular}

Sumber: Data diolah 


\begin{tabular}{|l|l|l|}
\hline Item & Kategori & mmortance \\
\hline T6 & 0 & 4,72 \\
\hline A2 & 0 & 4,63 \\
\hline T7 & 0 & 4,54 \\
\hline
\end{tabular}

\begin{tabular}{|l|l|l|}
\hline Hem & Kategori & mportance \\
\hline T1 & 0 & 4,72 \\
\hline T2 & 0 & 4,68 \\
\hline R3 & 0 & 4,67 \\
\hline R2 & 0 & 4,66 \\
\hline Al & 0 & 4,63 \\
\hline R4 & 0 & 4,59 \\
\hline RS4 & 0 & 4,58 \\
\hline T5 & 0 & 4,56 \\
\hline T4 & 0 & 4,54 \\
\hline
\end{tabular}

\begin{tabular}{|l|l|l|}
\hline Item & Kategori & Frqurtance \\
\hline RS1 & 0 & 4,52 \\
\hline A3 & 0 & 4,51 \\
\hline RS3 & 0 & 4,46 \\
\hline E3 & 0 & 4,46 \\
\hline E2 & 0 & 4,40 \\
\hline T9 & 0 & 4,35 \\
\hline E1 & 0 & 4,35 \\
\hline T8 & A & 4,14 \\
\hline
\end{tabular}

\begin{tabular}{|l|l|l|}
\hline Hem & Kategori & fmportance \\
\hline Rl & 0 & 3,77 \\
\hline
\end{tabular}

Sumber: Data diolah

\section{Gambar D.1 integrasi model IPA Kano}

\section{Pembahasan Cause and Effect Diagram}

Berdasarkan hasil perhitungan IPA dan Kano yang telah dilakukan, selanjutnya dilakukan analisis dengan menggunakan Cause effect diagram.

1. Tersedianya fasilitas internet dan wifi dengan koneksi yang cepat

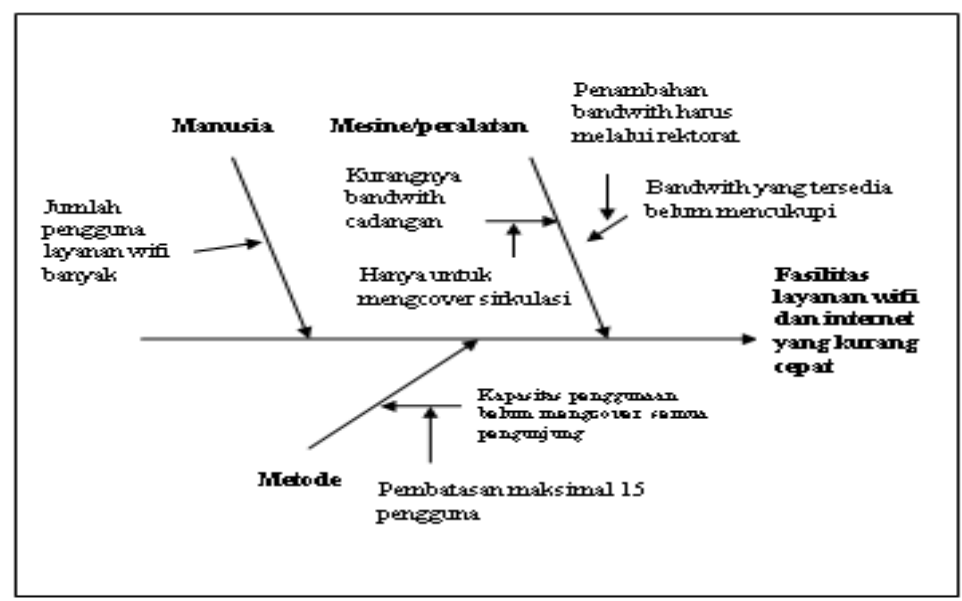

Sumber: hasil wawancara, diolah

Gambar D.2 Cause and Effect Diagram fasilitas internet dan wifi dengan koneksi yang cepat 
Tabel D.4 Usulan Perbaikan Atas Permasalahan Atribut Fasilitas Layanan Wifi dan Internet yang Cepat

\begin{tabular}{|c|c|c|}
\hline Faktor & Permasalahan & Usulan perbaikan \\
\hline Manusia & $\begin{array}{l}\text { Jumlah kedatangan } \\
\text { berfluktuatif dengan } \\
\text { keperluan yang bervariasi }\end{array}$ & $\begin{array}{l}\text { Menambah cadangan kuota } \\
\text { bandwith internet Perpustakaan } \\
\text { untuk mengantisipasi lonjakan } \\
\text { pengunjung yang dapat } \\
\text { menyebabkan pembagian } \\
\text { bandwith bertambah. }\end{array}$ \\
\hline \multirow[t]{2}{*}{ Mesin/peralatan } & $\begin{array}{l}\text { Bandwith yang tersedia } \\
\text { belum mencukupi } \\
\text { kebutuhan pelanggan }\end{array}$ & $\begin{array}{l}\text { Mengajukan penambahan } \\
\text { bandwith ke pihak Rektorat } \\
\text { Universitas agar mampu memenuhi } \\
\text { kebutuhan pengguna fasilitas } \\
\text { internet dan wifi Perpustakaan }\end{array}$ \\
\hline & $\begin{array}{l}\text { Kurangnya bandwith } \\
\text { cadangan apabila } \\
\text { bandwith yang tersedia } \\
\text { habis }\end{array}$ & $\begin{array}{l}\text { Menyiapkan bandwith cadangan } \\
\text { tersendiri yang dikhususkan untuk } \\
\text { memenuhi kebutuhan pelanggan, } \\
\text { dan bukan hanya digunakan untuk } \\
\text { sirkulasi karyawan. }\end{array}$ \\
\hline Metode & $\begin{array}{l}\text { Kapasitas penggunaan } \\
\text { wifi dan internet yang } \\
\text { belum mengcover semua } \\
\text { pengunjung }\end{array}$ & $\begin{array}{l}\text { Menambah kapasitas penggunaan } \\
\text { fasilitas wifi dan internet, menjadi } \\
\text { bukan hanya untuk } 15 \text { pelanggan, } \\
\text { sehingga mampu mencover } \\
\text { kebutuhan semua pengunjung } \\
\text { akan fasilitas wifi dan internet }\end{array}$ \\
\hline
\end{tabular}

Sumber: hasil observasi, diolah 
Fatrahman

Yetti Dwi Lestari

2. Petugas yang Bersikap Ramah, Sopan, Tertib, dan Rapi dalam Melayani Pengunjung

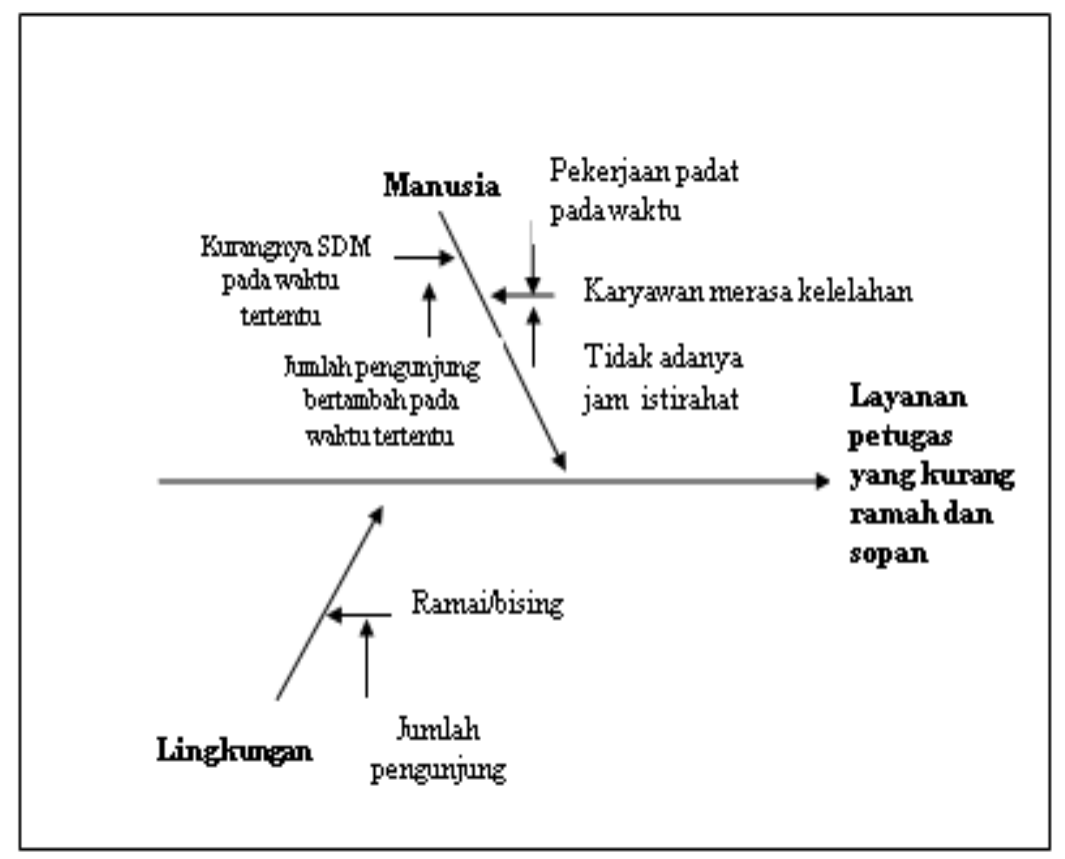

Sumber: hasil wawancara, diolah

Usulan Perbaikan Atas Permasalahan Atribut Petugas yang Bersikap Ramah, Sopan, Tertib, dan Rapi dalam Melayani Pengunjung

\begin{tabular}{|l|l|l|}
\hline Faktor & Permasalahan & Usulan perbaikan \\
\hline Manusia & $\begin{array}{l}\text { Kurangnya SDM pada } \\
\text { waktu tertentu }\end{array}$ & $\begin{array}{l}\text { Menambah SDM yang tersedia } \\
\text { dalam pelayanan untuk } \\
\text { mengantisipasi lonjakan } \\
\text { pengunjung }\end{array}$ \\
\cline { 2 - 3 } & $\begin{array}{l}\text { Petugas merasa } \\
\text { kelelahan pada saat } \\
\text { tertentu }\end{array}$ & $\begin{array}{l}\text { Pemberian jam istirahat untuk } \\
\text { karyawan guna menjaga kondisi } \\
\text { petugas dalam melayani } \\
\text { kebutuhan pengunjung }\end{array}$ \\
& $\begin{array}{l}\text { Lingkungan yang } \\
\text { ramai/bising }\end{array}$ & $\begin{array}{l}\text { Memberikan pelatihan kepada } \\
\text { karyawan agar mampu } \\
\text { memberikan pelayanan yang } \\
\text { ramah dan sopan dalam berbagai } \\
\text { kondisi }\end{array}$ \\
\hline
\end{tabular}

Sumber: hasil observasi, diolah 


\section{Tersedianya Fasilitas Toilet yang Bersih}

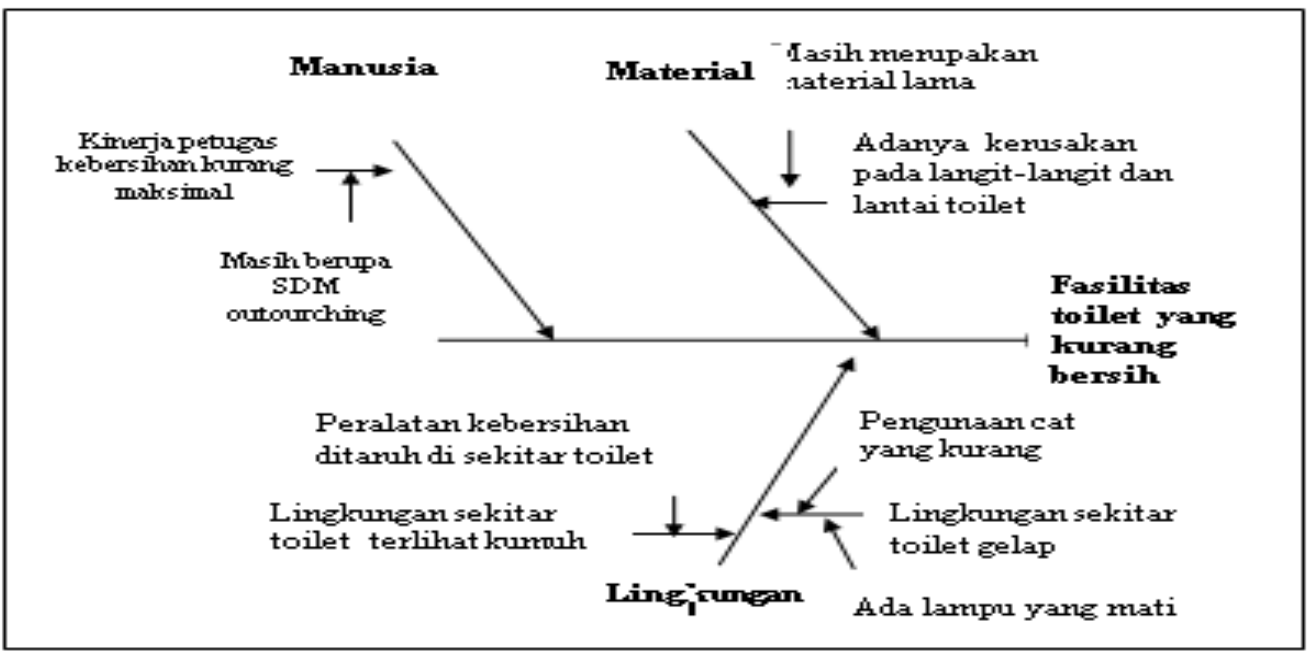

Usulan Perbaikan Atas Permasalahan Atribut Tersedianya Fasilitas Toilet yang Bersih

\begin{tabular}{|c|c|c|}
\hline Faktor & Permasalahan & Usulan perbaikan \\
\hline Manusia & $\begin{array}{l}\text { Kinerja petugas kebersihan } \\
\text { kurang maksimal }\end{array}$ & $\begin{array}{l}\text { Memberikan arahan dan } \\
\text { pelatihan internal kepada } \\
\text { petugas kebersihan agar } \\
\text { mampu meningkatkan skill dan } \\
\text { kemampuan petugas }\end{array}$ \\
\hline Material & $\begin{array}{l}\text { Adanya kerusakan pada } \\
\text { dinding dan lantai toilet }\end{array}$ & $\begin{array}{l}\text { Mengganti dinding dan lantai } \\
\text { toilet serta memperbaiki } \\
\text { kerusakan yang terjadi pada } \\
\text { atap toilet }\end{array}$ \\
\hline \multirow[t]{2}{*}{ Lingkungan } & $\begin{array}{l}\text { Lingkungan toilet yang } \\
\text { terkesan kumuh }\end{array}$ & $\begin{array}{l}\text { Memaksimalkan fasilitas gudang } \\
\text { yang ada, sehingga petugas } \\
\text { tidak lagi menaruh alat-alat } \\
\text { kebersihan di lingkungan sekitar } \\
\text { toilet }\end{array}$ \\
\hline & $\begin{array}{l}\text { Lingkungan toilet yang } \\
\text { terkesan gelap }\end{array}$ & $\begin{array}{l}\text { Mengganti cat interior dan } \\
\text { eksterior toilet dengan warna- } \\
\text { warna yang lebih cerah, serta } \\
\text { memperbaiki fasilitas lampu } \\
\text { didalam dan di sekitar toilet }\end{array}$ \\
\hline
\end{tabular}

Sumber: hasil observasi, diolah 


\section{Fatrahman}

\section{Yetti Dwi Lestari}

\section{E. SIMPULAN DAN SARAN}

SIMPULAN

- Melalui integrasi importance performance analysis dengan meodel kano pada hasil kuisioner yang telah diisi oleh pengunjung perpustakaan kampus B Universitas Airlangga maka dapat dilihat bahwa ada 3 atribut yang menjadi prioritas utama untuk dilakukan perbaikan. Atribut-atribut tersebut adalah 1) tersedianya fasilitas internet dan wifi dengan koneksi yang cepat, 2) petugas bersikap ramah, sopan, tertib, dan rapi dalam melayani pengunjung, 3) tersedianya fasilitas toilet yang bersih

- Usulan perbaikan yang dapat diberikan terhadap atribut-atribut yang menjadi prioritas untuk dilakukan perbaikan berdasarkan Cause and Effect Diagram ysng telah dilakukan, yaitu:

1. Menambah cadangan kuota bandwith internet Perpustakaan

2. Mengajukan penambahan bandwith ke pihak Rektorat Universitas

3. Menyiapkan bandwith cadangan tersendiri yang dikhususkan untuk memenuhi kebutuhan pelanggan

4. Menambah kapasitas penggunaan fasilitas wifi dan internet, menjadi bukan hanya untuk 15 pelanggan

5. Menambah SDM yang tersedia dalam pelayanan

6. Pemberian jam istirahat untuk karyawan guna menjaga kondisi petugas

7. Memberikan pelatihan kepada karyawan agar mampu memberikan pelayanan yang ramah dan sopan dalam berbagai kondisi

8. Memberikan arahan dan pelatihan internal kepada petugas kebersihan agar mampu meningkatkan skill dan kemampuan petugas

9. Mengganti dinding dan lantai toilet serta memperbaiki kerusakan yang terjadi pada atap toilet

10. Memaksimalkan fasilitas gudang yang ada

11. Mengganti cat interior dan eksterior toilet dengan warna-warna yang lebih cerah

\subsection{Saran}

Berdasarkan atas hasil analisis dan pembahasn dari penelitian, terdapat beberapa saran yang dapat diberikan dan diharapkan bisa bermanfaat, yaitu:Sebaiknya pihak manajemen Perpustakaan Kampus B Universitas Airlangga bisa memberikan perhatian lebih pada atribut-atribut kualitas pelayanan yang diprioritaskan untuk dilakukan perbaikan. Untuk mencapai kualitas pelayanan yang lebih baik, maka dibutuhkan peran dan dukungan dari seluruh pihak manajemen Perpustakaan Kampus B Universitas Airlangga untuk saling 


\section{Jurnal Manajemen Teori dan Terapan Tahun 8. No. 2, Agustus 2015}

membentu agar dapat meningkatkan kualitas pelayanan serta melakukan evaluasi kualitas layanan secara periodeik, agar mereka dapat melakukan perbaikan terhadap kualitas pelayanan yang masih kurang memuaskan bagi konsumen

\section{DAFTAR PUSTAKA}

Bayraktaroglu, Gul and OzgeOzgen. 2007 Integrating the kano model, AHP and planning matrix. Library Management. 29 (4/5): 327-351

Bilsel, et al. 2012. Ishikawa Cause and Effect Diagrams Using Capture Recaptive Recapture Techniques. 9(2): 137-152.

Deng, W.J., et al. 2008. Revised Importance-Performance Analysis: Three-factor Theory and Benchmarking. The Service Industries Journal. 28: 37-51.

Fatorahman, Fatorahman dan Yetty Dwi Lestari, 2014. Analisis Kualitas Layanan Perpustakaan Kampus B Universitas Airlangga Melalui Integrasi Importance Performance Analysis (IPA), dan Model Kano Serta Usulan Perbaikannya Menggunakan Cause And Effect Diagram, Program Studi S1 Manajemen Universitas Airlangga, 141.

Foster, S. Thomas 2004. Managing Quality: An Integrative Approach. Edisi Ketiga. New Jersey: Pearson Education, Inc.

Gasperz, Vincent. 2003. Metode Analisis Untuk Peningkatan Kualitas. jakarta: Gramedia Pustaka Utama

Koetler, Philip \& Keller, Kevin L. 2007. Manajemen Pemasaran. Edisi kedua belas. jakarta: PT Indeks.

Koetler, Philip \& Keller, Kevin L. 2007. Manajemen Pemasaran. Edisi kedua belas. jakarta: PT Indeks.

Kuo, Ying-Feng, et al. 2012. IPA-Kano Model: A New Tool for Categorizing and Diagnosing Service Quality Attributes. Total Quality management \& Bussiness excelence. 23 (7-8): 731748

Sahney, Sangeeta et al. 2003. Enchanching Quality In Education: Aplication of Quality Function Deployment-an Industry Perspective. Work Study. 52(6): 297-309.

Soeatminah. 1992. Perpustkaan, Kerpustakaan dan Pustakawan. Yogyakarta: Kanisius.

Sugiyono. P.D. 2010. Metode Penelitian Bisnis. Bandung: Alfabeta.

Thio, Sienny. 2001. Membangun Service Quality Untuk Mencapai Kepuasaan Konsumen di Industri Hospitality. Journal Manajemen dan Kewirausahaan: 3(1): 48-60.

Tjiptono, fandy. 201 1. Pemasaran Jasa. Malang: Byumedia. 
Fatrahman

Yetti Dwi Lestari

Yamit, Zulian. 2005. Manajemen Kualitas Produk dan Jasa. Yogyakarta: Ekonisia Kampus Fakultas Ekonomi UII Yogyakartaa.

Yuzahri, haeryi Sihombing, et al, 2012. Revisited The Importance- Performance Analysis (IPA) and Kano Model for Customer Satisfcation Measurement. Global Engineers \& Technologies Review. Vol 2 No. 1 